\title{
Simulation in surgical education: resident's point of view
}

\author{
Francisco Laxague ${ }^{\wedge}$ \\ Department of Surgery, Hospital Alemán of Buenos Aires, Buenos Aires, Argentina \\ Correspondence to: Francisco Laxague, MD. Department of Surgery, Hospital Alemán of Buenos Aires, Av. Pueyrredon 1640, C1118AAT, Buenos \\ Aires, Argentina. Email: flaxague@hospitalaleman.com.
}

\begin{abstract}
Changes in healthcare system, such as implementation of working hours' restrictions in residency programs, and ethical and patient's security regulations, have modified the methods and available time for trainee's education. These restrictions, have motivated the creation of novel teaching tools for a complete and successful education. Currently, simulation is one of the most implemented teaching methods globally. Fortunately, different simulation models have been developed: Virtual simulation, simulation in living animals, human and animal cadavers, box-training simulation, and 3D printed artificial models, among others. Nevertheless, each of these simulation models have their own advantages and disadvantages. Surgical skills development, improvements of perioperative results, decrease in hospital stay, and reduced costs are some advantages associated with simulation. Lack of homogeneous simulation programs, and costs of acquisition and maintenance of the equipment are drawbacks of surgical simulation. Surgical simulation is particularly attractive because it allows trainees to develop surgical skills in a "real-life", controlled, and safe scenario. This avoids practicing in a clinical environment, which potentially increases patient's safety, reduces perioperative complications, and decreases costs. In the last decades, surgical simulation has been gaining popularity in most residency programs worldwide, with a protected time for this activity. As a resident, I think that simulation is a great and useful teaching tool that should be part of all surgical residency curriculums.
\end{abstract}

Keywords: Surgical simulation; residents simulation; surgical training

Received: 01 June 2021; Accepted: 18 June 2021; Published: 30 September 2021.

doi: 10.21037/asj-21-41

View this article at: https://dx.doi.org/10.21037/asj-21-41

\section{Introduction}

The actual surgical educational model of progressive incorporation of skills and responsibilities was introduced by Dr. William Halstead in 1904 (1). This traditional method is based on the transfer of knowledge and skills from the mentor to the apprentice, requiring long and exhausting working hours (2).

In the last decade, a global reduction in working hours and surgical exposure time in the operating room for trainees has occurred due to the increasing burn-out syndrome among the residents (2). For this reason, original methods to reach the required knowledge and skills to become a surgeon have emerged in order to compensate these limitations.

Simulation in surgical training has gained an important role in residency programs. Simulation can provide a "realistic" scenario where trainees reproduce different surgical maneuvers and develop skills in a safe environment, providing patients a safer operation with a shorter learning curve (3).

This manuscript aimed to comment on the current use of simulation in the education of young surgeons from the residents' point of view.

\section{Simulation in surgical education}

Reports of medical errors in the operating room motivated

^ ORCID: 0000-0002-3140-883X. 
the development of training tools for surgical skills improvement (4). Surgical simulation is particularly attractive because it allows training in a controlled and safe scenario, avoiding practicing surgical maneuvers in patients. Currently, simulation is crucial in surgical training. Many surgical entities and societies strongly recommend the inclusion of simulation in the training curricula $(5,6)$. Apprentices can indeed acquire and develop basic surgical skills in a safe and controlled setting, which is an ethical way of acquiring skills and at the same time provide a better and safer surgical procedure to patients (7).

Different open, laparoscopic, and robotic simulation methods have been developed: Virtual simulation, simulation in living animals, human and animal cadavers, and box-training simulation, among others $(8,9)$. Although virtual simulation can reproduce a complete surgical procedure, costs and lack of haptic feedback are important drawbacks. Human cadavers and living animals are the most reliable models for surgical simulation. However, ethical concerns and costs are also limitations for their incorporation in simulation programs. Box lap trainers are more accessible, but only basic maneuvers can be practiced (9).

Simulation provides with realistic scenarios in which decisions to different events must be taken (10). Beyond being considered essential in the education of modern surgeons, some advantages and disadvantages can be highlighted regarding this teaching tool.

\section{Advantages}

Simulation reduces the learning curve of surgical procedures. In addition, it reduces operative time and perioperative complications, improves patient's outcomes, and reduces hospital stay and costs (11).

It has been demonstrated in well-designed studies that simulation improves technical skills in surgical trainees and significantly reduces intra-operative errors. In two prospective, randomized, blinded studies, it was shown that virtual reality simulation significantly improves outcomes of laparoscopic cholecystectomy performed by residents $(12,13)$. Thereby, patient's safety increases while reducing perioperative costs and increasing trainee's proficiency.

Current reduced working hours adopted globally in residency programs, motivated the incorporation of simulation programs. Through simulation, residents can train surgical maneuvers of a large number of procedures, compensating the reduced hours' of clinical duties (11).

\section{Disadvantages}

Surgical simulation could be a double-edged sword when mismanaged. Sometimes, trainees may adopt wrong habits if they train without a mentor's supervision. Therefore, it is crucial to incorporate certified simulation training programs with standardized progressions (14). In our hospital, we work with certified programs, adapted to each year of the residency with strict supervision by a senior surgeon.

Simulation complements the surgical training; it does not replace it. Thereby, it is essential for trainees, despite having access to the surgical simulation, to participate in as many surgical procedures in the operating room, as possible.

One of the main limitations of simulation is the costs of acquisition and maintenance of the equipment. The estimated costs of starting a simulation laboratory are about $\$ 1$ million, and maintenance expenses of all the infrastructure, are also very expensive. For non-developed countries is very hard to afford these programs. Fortunately, most of the simulation laboratories are funded by donations, research contributions, and/or industry support (15).

\section{Author's opinion}

Fortunately, we have a simulation center for open and laparoscopic surgery at our Institution. In the last years, simulation has represented an important component of our training, and we have protected time for this activity.

In my experience, simulation training gave me more confidence in the operating room. Surgical simulation allowed me to complete several steps of surgical procedures before operating a patient. In addition, as the reduced working hours (i.e., less time in the operating room) have in some way threatened my training, I found in simulation an effective method to compensate for this.

New generations have grown up in a time of rapid changes and are familiar with instant access to information through the internet. For this reason, residents in my hospital claim for rapid learning of the surgical technique. Through simulation, residents can shorten the learning curve time of the great majority of surgical procedures.

In conclusion, I think that simulation is a great and useful teaching tool that should be part of all surgical residency curriculums.

\section{Acknowledgments}

Funding: None. 


\section{Footnote}

Provenance and Peer Review: This article was commissioned by the Guest Editors (Fernando A. M. Herbella and Volha Raznitsyna) for the series "Modern Challenges in the Education of Young Surgeons: the Two Sides of the Coin" published in AME Surgical fournal. The article has undergone external peer review.

Conflicts of Interest: The author has completed the ICMJE uniform disclosure form (available at https://asj.amegroups. com/article/view/10.21037/asj-21-41/coif). The series "Modern Challenges in the Education of Young Surgeons: the Two Sides of the Coin" was commissioned by the editorial office without any funding or sponsorship. The author has no other conflicts of interest to declare.

Ethical Statement: The author is accountable for all aspects of the work in ensuring that questions related to the accuracy or integrity of any part of the work are appropriately investigated and resolved.

Open Access Statement: This is an Open Access article distributed in accordance with the Creative Commons Attribution-NonCommercial-NoDerivs 4.0 International License (CC BY-NC-ND 4.0), which permits the noncommercial replication and distribution of the article with the strict proviso that no changes or edits are made and the original work is properly cited (including links to both the formal publication through the relevant DOI and the license). See: https://creativecommons.org/ licenses/by-nc-nd/4.0/.

\section{References}

1. Halstead WS. The training of the surgeon. Johns Hopkins Hosp Bull 1904;15:267-75.

2. Elmore LC, Jeffe DB, Jin L, et al. National Survey of Burnout among US General Surgery Residents. J Am Coll Surg 2016;223:440-51.

3. Milburn JA, Khera G, Hornby ST, et al. Introduction, availability and role of simulation in surgical education and training: review of current evidence and recommendations from the Association of Surgeons in Training. Int J Surg 2012;10:393-8.

4. Darzi A, Smith S, Taffinder N. Assessing operative skill. Needs to become more objective. BMJ 1999;318:887-8.

5. Fitzgerald JE, Giddings CE, Khera G, et al. Improving the future of surgical training and education: consensus recommendations from the Association of Surgeons in Training. Int J Surg 2012;10:389-92.

6. Steinemann S, Gardner A, Aulet T, et al. American College of surgeons /Association for Surgical Education Medical Student Simulation-based Surgical Skills Curriculum: Alignment with Entrustable Professional Activities. Am J Surg 2019;217:198-204.

7. Moorthy K, Munz Y, Jiwanji M, et al. Validity and reliability of a virtual reality upper gastrointestinal simulator and cross validation using structured assessment of individual performance with video playback. Surg Endosc 2004;18:328-33.

8. Munz Y, Kumar BD, Moorthy K, et al. Laparoscopic virtual reality and box trainers: is one superior to the other? Surg Endosc 2004;18:485-94.

9. Schlottmann F, Murty NS, Patti MG. Simulation Model for Laparoscopic Foregut Surgery: The University of North Carolina Foregut Model. J Laparoendosc Adv Surg Tech A 2017;27:661-5.

10. Issenberg SB, McGaghie WC, Hart IR, et al. Simulation technology for health care professional skills training and assessment. JAMA 1999;282:861-6.

11. Zendejas B, Cook DA, Bingener J, et al. Simulationbased mastery learning improves patient outcomes in laparoscopic inguinal hernia repair: a randomized controlled trial. Ann Surg 2011;254:502-9; discussion 509-11.

12. Seymour NE, Gallagher AG, Roman SA, et al. Virtual reality training improves operating room performance: results of a randomized, double-blinded study. Ann Surg 2002;236:458-63; discussion 463-4.

13. Ahlberg G, Enochsson L, Gallagher AG, et al. Proficiencybased virtual reality training significantly reduces the error rate for residents during their first 10 laparoscopic cholecystectomies. Am J Surg 2007;193:797-804.

14. Vassiliou MC, Dunkin BJ, Marks JM, et al. FLS and FES: comprehensive models of training and assessment. Surg Clin North Am 2010;90:535-58.

15. Harrington DT, Roye GD, Ryder BA, et al. A time-cost analysis of teaching a laparoscopic entero-enterostomy. J Surg Educ 2007;64:342-5.

doi: 10.21037/asj-21-41

Cite this article as: Laxague F. Simulation in surgical education: resident's point of view. AME Surg J 2021;1:16. 